\section{Review \\ Correspondence \\ P. C. F. Oyston \\ pcoyston@dstl.gov.uk}

\title{
Q fever: the neglected biothreat agent
}

\author{
P. C. F. Oyston and C. Davies \\ Biomedical Sciences, Defence Science and Technology Laboratory, Porton Down, Salisbury, \\ Wiltshire SP4 OJQ, UK
}

\begin{abstract}
Coxiella burnetii is the causative agent of $\mathrm{Q}$ fever, a disease with a spectrum of presentations from the mild to fatal, including chronic sequelae. Since its discovery in 1935, it has been shown to infect a wide range of hosts, including humans. A recent outbreak in Europe reminds us that this is still a significant pathogen of concern, very transmissible and with a very low infectious dose. For these reasons it has also featured regularly on various threat lists, as it may be considered by the unscrupulous for use as a bioweapon. As an intracellular pathogen, it has remained an enigmatic organism due to the inability to culture it on laboratory media. As a result, interactions with the host have been difficult to elucidate and we still have a very limited understanding of the molecular mechanisms of virulence. However, two recent developments will open up our understanding of $C$. burnetii: the first axenic growth medium capable of supporting cell-free growth, and the production of the first isogenic mutant. We are approaching an exciting time for expanding our knowledge of this organism in the next few years.
\end{abstract}

\section{Taxonomy}

In 1935, in two near concurrent incidences on two different continents, a previously undescribed organism was identified. In Brisbane, Australia, E. H. Derrick had been tasked to investigate a febrile illness of unknown aetiology in abattoir workers, which led to him naming the disease Q (for query) fever (Derrick, 1937). His experimental work showed that he was able to transmit the fever to guinea pigs in blood and urine from infected patients, but was unable to isolate or identify the infectious agent. He sent a guinea pig liver to Burnet and Freeman. Their investigation noted 'intracellularly situated bodies which appear to be typical Rickettsiae' in smears from the spleens of infected mice (Burnet \& Freeman, 1983). They therefore named the organism Rickettsia burnetii. Meanwhile, on the other side of the Pacific in Montana, USA, a tick transmission study examining Rocky Mountain spotted fever recovered an unknown infectious agent capable of passing through filters. When injected into guinea pigs, this agent produced unexpected clinical signs (Davis \& Cox, 1938). This agent, named the Nine Mile agent, displayed properties of both bacteria and viruses, and they were unable to grow the organism on axenic medium. Later, Cox reported a breakthrough in the ability to culture the organism in tissue culture and embryonated eggs (Cox \& Bell, 1939). A laboratory-acquired infection with the Nine Mile agent in Montana led to the discovery that the Australian and American groups were investigating the same organism. It was proposed to rename the organism Coxiella burnetii to credit both groups for their pioneering research into this newly identified infectious agent.

The historical classification of the aetiological agent of $Q$ fever as a Rickettsia was due to the shared characteristics of being an obligate intracellular organism and having a tick reservoir. However, the restructuring of the family Rickettsiaceae based on genetic differences resulted in the organism becoming a member of the family Coxiellaceae in the order Legionellales. More recently, $16 \mathrm{~S}$ rRNA sequencing placed Coxiella into the gamma subdivision of Proteobacteria, with Legionella, Francisella and Rickettsiales being its closest, although rather distant, relatives (reviewed by Maurin \& Raoult, 1999). Molecular techniques have subsequently shown considerable variation between isolates, although there does appear to be clustering based upon geographical origin (Maurin \& Raoult, 1999).

\section{Bacteriology}

C. burnetii is a small $(0.2$ to $1 \mu \mathrm{m})$ Gram-negative highly pleomorphic coccobacillus. The organism displays a typical Gram-negative cell wall structure, but does not stain reliably with Gram stain; for this reason the Gimenez stain has been used historically (Gimenez, 1964).

Similarly to Chlamydia, Coxiella has a unique intracellular lifestyle with two distinct morphological forms, the large cell variant (LCV) and the small cell variant (SCV) (McCaul \& Williams, 1981). They can be differentiated by size, morphology, peptidoglycan content and resistance to physical disruption. SCVs are the environmental extracellular form of the organism. They are 0.2 to $0.5 \mu \mathrm{m}$ long, compact and typically rod-shaped with an electron-dense core bounded by cytoplasmic and outer membranes (McCaul \& Williams, 1981). They are metabolically inactive, and show a high degree of resistance to chemical agents and physical conditions, such as osmotic pressure and sonic disruption (McCaul \& Williams, 1981), which 
confers the ability to survive for prolonged periods in the environment. In contrast, LCVs resemble Gram-negative bacteria, can exceed $1 \mu \mathrm{m}$ in length, but are more pleomorphic than the SCVs. They possess a thinner cell wall, with a more dispersed filamentous nucleoid region. They are metabolically active, and are the intracellular form of the organism. McCaul and Williams reported a 'sporelike particle' in the polar regions of some LCVs and thus they hypothesized that an endogenous spore was a part of the developmental cycle of C. burnetii (McCaul \& Williams, 1981). Further work showed that the spore-like particle did not stain with spore stains, and was not detected by tests for dipicolinic acid, a traditional spore marker (McCaul, 1991). It has been hypothesized that the 'spores' develop into SCVs, although these particles have never been isolated and purified, and thus this has not been proven as yet.

C. burnetii enters cells passively (Baca et al., 1993), and resides within a parasitophorous vacuole $(\mathrm{PV})$, which has been described as a structure similar to a secondary lysosome (Heinzen et al., 1999). The PV is an acidic environment $(\mathrm{pH} 4.7-4.8)$, and the low $\mathrm{pH}$ appears to trigger the conversion of SCVs to LCVs (Hackstadt \& Williams, 1981). Morphogenesis from SCV to LCV occurs during an initial lag phase with no increase in bacterial number (Coleman et al., 2004), before replication to high levels until it reaches stationary phase at around 6 days post-infection (Coleman et al., 2004). Intracellular growth is relatively slow, with a doubling time of approximately 8 12 h (Baca \& Paretsky, 1983).

The situation is complicated further by phase I and phase II forms. Phase variants display different LPS lengths with phase I organisms producing a full-length LPS with $\mathrm{O}$ antigen sugars, and phase II organisms producing a truncated LPS without $\mathrm{O}$ antigen (Schramek \& Mayer, 1982). This phase variation has been compared to the smooth and rough LPS variation found in Enterobacteriacae, with phase II equivalent to the rough LPS phase (Hackstadt et al., 1985), and is often, but not always, associated with chromosomal deletion of genes involved in LPS biosynthesis (Hoover et al., 2002; Denison et al., 2007). The phase I form is isolated from infected hosts, but not the phase II form. Only following serial passage in eggs or tissue culture can the phase II form be obtained (Fiset, 1957). Microscopically the two forms are indistinguishable, but the impact on the serological response is significant. The response to the phase II antigen is much higher during acute infection than chronic infection, whereas titres to phase I antigen are higher during chronic infection compared to acute infection (outlined in the publication by Olson et al., 2006). Although the phase II is attenuated for growth in primary mouse macrophages, the two forms do not differ for growth in other cells, including continuous cell lines and primary guinea pig macrophages (reviewed by Howe et al., 2010)

C. burnetii has a single circular chromosome (Seshadri et al., 2003). PFGE has indicated that the genome size ranges from 1500 to $2400 \mathrm{~kb}$ (Willems et al., 1998). The complete genome of the Nine Mile reference strain has been sequenced and the circular chromosome was found to be $1995275 \mathrm{bp}$ in length with a mol\% G + C content of $42.6 \%$ (Seshadri et al., 2003). Other isolates of C. burnetii have also been sequenced, and have been shown to possess genomes of very similar length. The Nine Mile strain also possesses a $37.4 \mathrm{~kb}$ plasmid, QpH1 (Samuel et al., 1983). Three other related plasmids carried by other strains of $C$. burnetii have also been described, designated QpDG, QpDV and QpRS (Valková \& Kazár, 1995; Mallavia, 1991). The plasmids share significant regions of homology, but also have plasmid-specific sequences, which can be used to differentiate the plasmids (Jäger et al., 2002; Lautenschläger et al., 2000). Plasmidless strains possess plasmid-homologous sequences integrated into the chromosome (Willems et al., 1997; Savinelli \& Mallavia, 1990), which implies a critical function for the core plasmid genes. C. burnetii shows a similarity in lifestyle to Rickettsia and Chlamydia, but differs significantly with regard to genetic structure. For example, the proportion of pseudogenes is lower than seen in many other intracellular pathogens, suggesting that genome reduction may have started relatively recently in Coxiella (Seshadri et al., 2003). Also, compared to the many other obligate intracellular pathogens, C. burnetii possesses many copies of insertion sequence (IS) elements. Interestingly, the IS elements are only located in the chromosome of the Nine Mile genome, with no copies in the plasmid (Seshadri et al., 2003). Multiple copies of IS elements appear to mediate genomic plasticity in C. burnetii (Beare et al., 2009b), similarly to that seen in other intracellular pathogens that are relatively recently emerged, such as Yersinia pestis (Parkhill et al., 2001). Unravelling the pathogenic mechanisms involved in the host-pathogen interactions has been difficult, due to the inability to genetically manipulate $C$. burnetii. This has been circumvented by using surrogate hosts to assess various functions, such as Escherichia coli (Suhan et al., 1994) and Legionella pneumophila (Zamboni et al., 2003; Zusman et al., 2003). Recently, however, Himarl transposon mutagenesis was employed to create an $f t s Z$ mutant in Coxiella (Beare et al., 2009a), a method that was previously used to create mutants in the obligate intracellular organisms Anaplasma phagocytophilum (Felsheim et al., 2006) and Rickettsia prowazekii (Liu et al., 2007).

\section{Culture}

Due to the high infectivity of the pathogen and the disease that ensues, the organism should only be handled under bio-safety level 3 containment. Historically, cultivation of the organism was performed in guinea pigs. This practice is not as widely used in modern science; however, it is an excellent procedure for isolating C. burnetii from contaminated samples, and passage through guinea pigs ensures isolation of phase I organisms from mixed cultures (Maurin \& Raoult, 1999). Spleen extracts from the infected animals can then be propagated in embryonated eggs. Yolk 
sac inoculation of 5-7-day-old embryonated eggs, with incubation for 10-12 days, produces a high yield in the yolk sac, specifically the yolk sac membrane, with lower numbers found within the tissues of the embryo (reviewed by Baca \& Paretsky, 1983). The yolk sac is then harvested. During their biowarfare offensive programme, however, the US harvested the entire egg minus shell (Tigertt et al., 1961). C. burnetii can infect a range of cells, including monocytes and macrophages, and cell lines, including macrophages, fibroblast and epithelial cells (reviewed by Maurin \& Raoult, 1999). Indeed, antibiotic susceptibility profiling has usually been undertaken in cell culture models, but results obtained in these screens were not always replicated in the clinic (Levy et al., 1991). Care must be taken with repeated passage through eggs or cell lines as phase II variants can arise as mentioned above.

Following growth of the organism, purification is laborious and time-consuming, involving several differential centrifugation steps, followed by density-gradient centrifugation steps. This process has been evaluated and improved over time (Cockrell et al., 2008; Williams et al., 1981; Davis \& Patrick, 1965; Ormsbee, 1962), but still remains an involved process.

A massively important development reported recently was the first cell-free laboratory medium for the growth of $C$. burnetii. Omsland et al. (2009) developed an acidified citrate cysteine medium. By evaluating the organism's metabolic requirements by transcriptomics, metabolic typing and pathway analysis, a complex medium was developed. The acidic medium ( $\mathrm{pH} 4.75$ ) and low oxygen tension $(2.5 \%)$ were designed to mimic conditions in the PV. A heavy starting inoculum was required, but a $3 \log _{10}$ increase was detected after 6 days culture. Moreover the medium and environment facilitates the transition from SCV to LCV. This is an enormous breakthrough that will greatly facilitate studies into the biology and pathogenesis of Coxiella.

\section{Ecology, epidemiology and vectors}

Human Q fever has been described in countries around the world with the exception of New Zealand (Hilbink et al., 1993). As it is not a notifiable disease in many countries, the geographical distribution of the organism is extrapolated from serological surveys and investigated outbreaks (Maurin \& Raoult, 1999). It is also considered that the actual incidence of human infection is under-reported due to the difficulty in diagnosis and asymptomatic infections that can only be identified by seroconversion (Raoult, 2009). It is believed to be ubiquitous in the environment as was shown recently in a 3 year study across the USA (Kersh et al., 2010), where geographically diverse areas, both agricultural and urban, were sampled. The organism has reservoirs in a wide range of wild and domestic animals, including mammals, birds and arthropods (reviewed by Maurin \& Raoult, 1999), although the true extent of the reservoirs is unknown. Of greatest relevance to human disease are domestic ruminants, which are the most common source of human infections (Dupuis et al., 1987; Fishbein \& Raoult, 1992; Marrie et al., 1985).

C. burnetii infection of livestock is termed coxiellosis, a chronic but often symptomless disease. The uterus and mammary glands are sites of chronic infection in females, and this is associated with abortions in goats and sheep, and infertility in cattle (Palmer et al., 1983; Rady et al., 1985; To et al., 1998). C. burnetii is shed from milk, urine and faeces. At birth, the placenta contains vast quantities of Coxiella, which are released into the environment. Farming practices can facilitate environmental spread, such as transport of infected animals and the spreading of contaminated manure onto fields (Enserink, 2010). This, together with the environmental stability of the organism, pose a difficulty in containing outbreaks, as has been noted in the recent outbreak in the Netherlands (Enserink, 2010).

A range of arthropods, including ticks, have been shown to be able to be colonized via ingestion of contaminated blood feeds. These ticks release significant quantities of Coxiella in their faeces. While experimental transmission between guinea pigs has been achieved via tick bite (Smith, 1940, 1941), arthropod vectors are not considered essential to the natural cycle of infection in livestock that live closely together and likely contract the organism from close contact with other infected animals (Babudieri, 1959). However, ticks may play an important role in transmission in the wild, for example between birds (Stein \& Raoult, 1999; Babudieri, 1959).

\section{Decontamination and control measures}

C. burnetii is known to be resistant to physical stresses, such as elevated temperature, desiccation, osmotic shock and UV light, and to chemical stresses, such as disinfectants, which contributes to its stability in the environment. In the UK, Health Protection Agency guidelines (at www.hpa.org.uk/ deliberate_accidental_releases/biological) suggest the use of $2 \%$ formaldehyde, $1 \%$ Lysol, $5 \%$ hydrogen peroxide, $70 \%$ ethanol or $5 \%$ chloroform for decontamination of surfaces, and spills of contaminated material should be dealt with immediately using hypochlorite (5000 p.p.m. available chlorine), $5 \%$ peroxide or phenol-based solutions. However, they also state that 'It is impossible to decontaminate large areas of a potentially contaminated environment'. Formaldehyde vapour was ineffective without humidity control (despite inactivating Bacillus spores under these conditions), but effective when a high relative humidity was maintained (Scott \& Williams, 1990). Although areas thought to be contaminated could be assessed for presence of C. burnetii DNA by PCR (Kersh et al., 2010; Fitzpatrick et al., 2010), determining viability would be difficult, and combined with the organism's resistance to chemical disinfectants, assessing decontamination efficacy would be difficult.

Tick control and good hygiene procedures can reduce the incidence in livestock (reviewed by Angelakis \& Raoult, 
2010). Contaminated bedding and high risk materials, such as aborted fetuses, should be buried with lime or incinerated. Manure from infected herds should be treated with lime or calcium cyanide before spreading on land. In addition, spreading on a relatively calm day will reduce the risk of wind transmitting infectious material for large distances. Separating infected animals from the herd and restricting animal movements from infected areas may also help to reduce spread.

The recent $\mathrm{Q}$ fever outbreak in the Netherlands has shown how difficult it is to contain an outbreak in livestock due to airborne transmission (Enserink, 2010). Control measures during this ongoing outbreak have included the culling of infected animals and pregnant livestock in infected areas. Unfortunately, there is no means to quickly identify infected from healthy animals and vaccination is ineffective in infected animals. Vaccination of naive animals does not completely prevent infection, but does reduce abortion rates, which curtails the spread of the organism. A widespread programme of cattle vaccination in Slovakia significantly reduced the local incidence of $\mathrm{Q}$ fever (Kovácová \& Kazár, 2002). Antibiotic treatment of infected animals does not stop shedding and as such is ineffective in controlling the disease spreading (Astobiza et al., 2010).

\section{Animal models}

Q fever in man can manifest as either acute or chronic disease, thus there has been a search for animal models that mimic both human disease profiles. As Q fever is a disease arising from inhalation of infectious organisms, the most appropriate model should be an animal susceptible to inhalation challenge and that develops a disease similar to that seen in man. The guinea pig is one of the more familiar models of Q fever, being used for the first isolation of the pathogen. The route of infection, i.e. intranasal versus intraperitoneal, alters the pattern of pathology ( $\mathrm{La}$ Scola et al., 1997). An aerosol challenge model has been developed. In this model, the $\mathrm{LD}_{50}$ was calculated as $2 \times 10^{5.7}$ C. burnetii, although the infectious dose was significantly lower with animals receiving as few as 20 organisms developing fever (Russell-Lodrigue et al., 2006). Guinea pigs can also develop a latent infection that can be reactivated following immunosuppression (Sidwell et al., 1964a, b). Generally, the guinea pig is regarded as a model of acute $\mathrm{Q}$ fever in humans.

Mice have also been used as an infection model, but develop a chronic infection compared to the more acute guinea pig model, although endocarditis does not develop in normal adult mice. Similarly to the guinea pig, intranasal or intraperitoneal challenge does not result in clinical signs although pathology develops with high bacterial loads in the liver and spleen (Burnet \& Freeman, 1937; Scott et al., 1987), and the pathology varies with the challenge route (Marrie et al., 1996). Mice are chronically infected for months, with prolonged shedding of bacteria in faeces and urine. The susceptibility of the mice is dependent on the mouse strain (Scott et al., 1987), and resistant strains can be rendered susceptible by loss of the thymus, with the mice again developing a chronic infection (Kishimoto et al., 1978). Also, A/J mice defective in various immunological processes are highly susceptible to C. burnetii (Scott et al., 1987). Transgenic mice constitutively expressing interleukin 10 have been proposed as an improved murine model for chronic Q fever (Meghari et al., 2008). Cardiac valve damage has been reported in mice immunosuppressed with cyclophosphamide prior to challenge (Atzpodien et al., 1994), and in pregnant mice inoculated intraperitoneally with C. burnetii (Stein et al., 2000).

A non-human primate model based on the cynomolgus and rhesus macaques infected by the aerosol route has also been reported (Gonder et al., 1979; Waag et al., 1999). Animals developed pneumonia and fever 4-7 days postchallenge, and thus represent the closest representation of the disease in man. However, although a non-human primate model would be required for licensing new medical countermeasures, such as vaccines, it would be unethical to perform most basic research in such a model. Thus, the guinea pig and mouse remain the most common laboratory animal models, despite their limitations, and can be supplemented with observations gained with infected egg and cell culture models.

\section{Disease in humans}

Q fever was first documented in abattoir workers in Queensland, Australia. The lack of a diagnosis based on vague febrile symptoms led to the illness being designated Query (Q) fever (Derrick, 1937). Although C. burnetii infection can result in outcomes from asymptomatic seroconversion to death, fever and pneumonia are the typical clinical manifestations, although other complications including hepatitis and endocarditis can also develop (reviewed by Maurin \& Raoult, 1999). Typically, infection in humans arises by inhalation of infectious aerosols produced by farm animals and pets, although infection has also been shown to arise by ingestion of infected dairy products (reviewed by Angelakis \& Raoult, 2010). Although, as described above, ticks are important vectors for the transmission of $C$. burnetii between wild animals, they do not transmit the infection to humans (Kazár, 1996). Person-to-person transmission is rare but has been documented. For example C. burnetii has been identified in the semen of infected males, and this has resulted in sexual transmission of the pathogen (Miceli et al., 2010; Milazzo et al., 2001). Chronic Q fever can develop many months or years after infection, manifesting in the majority of cases as culture-negative endocarditis (Gami et al., 2004), and more rarely as osteomyelitis, osteoarthritis, hepatitis and other diverse manifestations (reviewed by Angelakis \& Raoult, 2010). One chronic outcome to acute $Q$ fever is post- $Q$ fever fatigue syndrome. This syndrome develops in approximately $15 \%$ of patients recovering from acute 
infection, can be disabling in severity and can persist for up to a decade (Marmion et al., 1996; Ayres et al., 1996, 1998). The fatigue syndrome has been attributed to a dysregulation of cytokine production, induced by persistent antigens including LPS and proteins, rather than persistent latent Coxiella (Marmion et al., 2009).

C. burnetii has been identified by organizations such as the World Health Organization (WHO), the United Nations and the Australia Group as an agent of concern (WHO, 2004). Indeed it featured in offensive weapons programmes in the USA and former Soviet Union in the last century (reviewed by Waag, 2007). In the event of a biological attack, it is likely that the pathogen will be delivered as an aerosol. Inhalation of $C$. burnetii results in pneumonic disease, and the infectious dose is as low as 1-10 c.f.u. (Tigertt et al., 1961). Following inhalation, symptoms can develop after 10 to 90 days, depending on the dose. Lower doses often result in an asymptomatic outcome or mild cases characterized by a non-productive cough, fever and minimal abnormalities to normal breathing sounds. However, acute pneumonic Q fever can result in respiratory distress. The mortality rate ranges from 0.5 to $1.5 \%$ (Tissot Dupont et al., 1992). In a study to estimate the effect of $\mathrm{Q}$ fever used as a bioweapon, the WHO estimated that if $50 \mathrm{~kg} C$. burnetii were aerosolized over an urban area with 500000 inhabitants, there would be 125000 cases of acute illness, 9000 cases of chronic Q fever and 150 fatalities (WHO, 1970). During the ongoing outbreak of Q fever in the Netherlands, as of November 2009, 2293 human cases had been confirmed, including 6 deaths, showing that the mortality rate used by WHO in their assessment erred on the conservative side, so the impact of a bioweapon attack with $\mathrm{Q}$ fever may in fact be more severe. In 2010, there were a further 421 human cases, and 5 potential fatalities, reported up to June 2010 by the Netherlands authorities, indicating that the stringent control measures of culling and vaccination of livestock may be having an impact and bringing the outbreak under control.

The low aerosol infectious dose of $\mathrm{Q}$ fever for man can be stated with some confidence as, unlike many pathogens, classical biothreat agents have been used to deliberately infect humans, providing information on infectious dose, incubation period and development of symptoms. These experiments were performed in the USA on conscientious objectors, who wished to serve their country without taking up arms. The experiments were collectively referred to as Operation Whitecoat and one of the pathogens included was $C$. burnetii. In addition to understanding the disease and the pathogen, Operation Whitecoat also aimed to evaluate medical countermeasures against threat pathogens. The studies involving $\mathrm{Q}$ fever were the first conducted during Operation Whitecoat, and were referred to as CD-22. In January 1955, volunteers were exposed to indoor aerosols of $C$. burnetii at the US Army's research facility at Fort Deitrick (Frederick, USA). The aim of these studies was to determine the minimal infectious dose for humans and evaluate the efficacy of vaccination. Young adult male volunteers were exposed to aerosolized Q fever produced as an egg slurry (Tigertt et al., 1961). After inhalation of 101 volumes of the aerosol, the volunteers were monitored for the development of a persistent fever over $100^{\circ} \mathrm{F}$ (Table 1 ), after which they were treated with oxytetracycline to clear the infection. It was also found that oral dosing with the same therapy post-exposure, but before the development of symptoms, was effective in preventing disease (Tigertt et al., 1961). Vaccination was able to protect against even extremely high challenge levels. Subsequently in July of the same year the volunteers, together with guinea pigs and primates, were exposed to Q fever under conditions mimicking a biological attack. To this end, aerosols of $\mathrm{Q}$ fever were released 3000 feet $(914.4 \mathrm{~m})$ away from the test subject, at night, in the desert at the Dugway Proving Ground in Utah. The test was aimed to deliver 150 infectious units to each individual (Tigertt et al.,1961). Individuals were treated with antibiotics at the end of the study, and all recovered. Considering the chronic sequelae associated with Q fever, longer term follow up was conducted on those volunteers, but no sequelae were identified (Pittman et al., 2005).

Due to the wide range of presentations of disease and difficulties in culturing the pathogen on laboratory media, the clinical diagnosis of C. burnetii is most commonly reliant on seroconversion detected by immunofluorescence assays (reviewed by Maurin \& Raoult, 1999). However, a lag in seroconversion during the early stages of infection can confound diagnosis. Thus, PCR-based methods have been developed for direct detection in clinical samples

Table 1. Infection of guinea pigs and humans with C. burnetii following inhalational exposure as reported by Tigertt et al. (1961)

\begin{tabular}{|c|c|c|c|c|}
\hline $\begin{array}{l}\text { Dose of } C . \text { burnetii } \\
\text { (guinea pig infecting dose) }\end{array}$ & $\begin{array}{c}\text { Seroconversion of guinea } \\
\text { pigs (positive/exposed) }\end{array}$ & $\begin{array}{l}\text { Time to onset } \\
\text { of fever (days) }\end{array}$ & $\begin{array}{l}\text { Seroconversion of man } \\
\quad \text { (positive/exposed })\end{array}$ & $\begin{array}{l}\text { Time to onset } \\
\text { of fever (days) }\end{array}$ \\
\hline 1 & $0 / 29$ & 12.5 & $0 / 2$ & 17 \\
\hline $10^{2}$ & $4 / 24$ & 11 & $7 / 8$ & 15 \\
\hline $10^{3}$ & $22 / 27$ & 9 & $4 / 5$ & 13.5 \\
\hline $10^{4}$ & $28 / 28$ & 8.5 & $4 / 4$ & 10.5 \\
\hline
\end{tabular}


(Fenollar \& Raoult, 2007; Klee et al., 2006; Fenollar et al., 2004; Schneeberger et al., 2010). Recently, serological and molecular methods were compared in the on-going outbreak in the Netherlands (Schneeberger et al., 2010): real-time PCR was effective at detecting C. burnetii DNA during the early stages of infection, but an immunofluorescence assay was more reliable once an antibody response developed as the immune response resulted in circulating organism being suppressed below detectable levels.

Laboratory evaluation of antibiotic susceptibility has been complicated by the inability to culture $C$. burnetii on laboratory media. As such, complex assays involving egg infections and cell culture models have been employed, but have given somewhat confusing and contradictory results (reviewed by Maurin \& Raoult, 1999). Also, promising performance in vitro is not always replicated in the clinic, for example, as was seen for fluoroquinolones (Levy et al., 1991). Therapeutic regimens are dependent upon whether the patient is suffering from acute or chronic Q fever. Doxycycline (200 mg daily for 14 days) is the current drug of choice for acute $\mathrm{Q}$ fever, although other antibiotics such as chloramphenicol and co-trimoxazole have also been suggested as potential therapies. However, as most cases of acute $\mathrm{Q}$ fever are self-limiting it has been difficult to establish the clinical efficacy of such regimens, although it appears that therapy is of most benefit if initiated in the first 3 days of illness (Olson et al., 2006). Treatment of chronic Q fever requires protracted regimens, for periods of up to several years. Relapse is common upon withdrawal of the therapy. Maurin \& Raoult (1999) recommended patients with endocarditis be treated with doxycycline/ chloroquine for at least 18 months, or doxycycline/ ofloxacin for at least 3 years. The therapy can also be supported by valve replacement surgery (FernándezGuerrero et al., 1988; Kristinsson \& Bentall, 1967).

\section{Pathogenesis and immunity}

Following inhalation, the organism must first invade before subsequently causing systemic infection. The alveolar macrophage has been proposed as the primary target. It has been suggested that one factor contributing to the attenuation of phase II forms versus phase I forms is the nature of the interaction between the organism with host cells (Mege et al., 1997). However, recently it has been shown that the replication of phase I and phase II cells is very similar in human monocyte-derived macrophages (Howe et al., 2010). Once inside the cell, the organism resides in a modified vacuole with late endosome-lysosome characteristics, the PV (Berón et al., 2002; Heinzen et al., 1996; Howe \& Mallavia, 2000; Romano et al., 2007). Similarly to a wide range of Gram-negative pathogens, the LPS is a dominant virulence factor of C. burnetii. Indeed, it has been suggested that the structure of the LPS may influence acute versus chronic outcomes (Hackstadt, 1990; Baca \& Paretsky, 1983). LPS contributes to the uptake of virulent strains by a Toll-like receptor 4-dependent mechanism (Honstettre et al., 2004) and the two phases appear to interact with different surface receptors on macrophages (Capo et al., 2003). However, LPS does not appear to play a role in survival within the PV, as both phase I and II cells were observed within PVs, and even within the same PV of co-infected cells (Howe et al., 2010).

In acute cases in humans, $\mathrm{Q}$ fever presents as pneumonia and hepatitis (reviewed by Maurin \& Raoult, 1999). It is not known how C. burnetii infects systemically from the lungs, but most likely it is trafficked by infected phagocytic cells, and transient bacteraemia has been observed late in the incubation period. Kupffer cells are considered the primary target in the liver (reviewed by Maurin \& Raoult, 1999).

Once phagocytosed, the organism must resist killing following fusion of the lysosome. C. burnetii is welladapted to this niche, being an acidophilic organism, and requiring an acidic environment for many metabolic processes (Chen et al., 1990; Hackstadt \& Williams, 1983; Hendrix \& Mallavia, 1984; Zuerner \& Thompson, 1983). Acidification of the phagolysosome upon phagocytosis has been proposed as a possible trigger for activation of SCVs to form LCVs. The LCV is the intracellular, metabolically active form, which can undergo a division process, with similarities to sporulation, to generate SCVs, the metabolically inactive, highly resistant form released extracellularly to infect new susceptible cells (McCaul et al., 1991). A few proteins important for intracellular survival have been identified, including superoxide dismutase, catalase and macrophage infectivity potentiator (CbMip) (Mo et al., 1995; Akporiaye \& Baca, 1983). The CbMip protein shows homology to the FKBP family with peptidyl-prolyl-cis/trans isomerase activity. Several intracellular pathogens have been shown to produce FKBP-like proteins that have been shown to be important in pathogenesis, apparently by modulating cellular responses (reviewed by Hacker \& Fischer, 1993). CbMip is a secreted protein, and export is triggered in vitro by an acid pH (Redd \& Thompson, 1995), similarly to conditions that would be experienced in the phagolysosome. Interrogation of the genome sequence data from C. burnetii Nine Mile phase I RSA493 revealed little in the way of pathogenicity loci (Seshadri et al., 2003). However, a type IV secretion system was identified, similar to the Dot/Icm system of L. pneumophila (Vogel \& Isberg, 1999). C. burnetii encodes 23 of the $26 \mathrm{Dot} / \mathrm{Icm}$ proteins identified in L. pneumophila (Vogel, 2004). Mutation of some genes of the L. pneumophila secretion system can be complemented by some of the corresponding genes from C. burnetii, but not in all cases (Vogel, 2004; Zusman et al., 2003; Zamboni et al., 2003).The range of effectors identified that are proposed to be secreted by this system in L. pneumophila is large, with over 70 proteins identified (Ninio \& Roy, 2007), whereas effectors of C. burnetii remain elusive although attempts to identify them are under way (reviewed by Voth \& Heinzen, 2009). In Legionella the $\mathrm{Icm} /$ Dot system acts to prevent lysosome fusion, and then has profound effects on diverse cellular 
functions (reviewed by Franco et al., 2009). The genetic intractability of $C$. burnetii has impeded the discovery of effectors but there is gradual evidence accumulating as to the identity and function of some of the effectors. The bioinformatic analysis of the C. burnetii genome for features associated with type IV secretion system effectors identified proteins with features normally associated with eukaryotic proteins, indicating that they may have a role in the eukaryotic cell (Voth \& Heinzen, 2007). These features included coiled-coil domains, ankyrin repeats, leucine-rich repeats, GTPase domains, ubiquitination-related motifs and tetratricopeptide repeats, which are all normally rare in prokaryotic proteins. The first three features mentioned are usually involved in mediating protein-protein interactions, and could be predicted to act by direct action with host proteins following secretion. Other motifs indicate proteins that could exert their effects by regulating signal transduction pathways. Ankyrin repeat domain-containing proteins (Anks) have been identified in other intracellular pathogens including L. pneumophila, Anaplasma, Wolbachia and Rickettsia (reviewed by Voth et al., 2009), and in $L$. pneumophila many of the proteins secreted by the type IV secretion system are Anks. The Anks of C. burnetii have been shown to be secreted by the L. pneumophila Icm/Dot system (Voth et al., 2009), adding further weight to the hypothesis that these are some of the elusive effectors. As to function, Anks were shown to localize to various sites within the cell, which may give an indication of function: some localized to host microtubules and may thus impede microtubule functions; some localized to mitochondria, possibly to modulate apoptotic functions; while others were identified in the PV membrane, possibly to mediate vesicle fusion for maturation (Voth et al., 2009). Actin is recruited to, and involved in the formation of, the vacuole inhabited by C. burnetii (Aguilera et al., 2009). Actin dynamics are often regulated by Rho GTPases, and in HeLa cells the correct formation of the mature C. burnetii vacuole appeared to be dependent upon two such proteins, RhoA and Cdc42 (Aguilera et al., 2009). It has been hypothesized that the type IV secretion system effectors may have an effect on Rho GTPases, a theory supported by the observation that inhibition of $C$. burnetii protein synthesis by chloramphenicol inhibits Rho proteins being recruited to the vacuole. It is also supported by observations on other intracellular pathogens, such as Legionella, Leishmania and Chlamydia, where Rho GTPases are similarly important (reviewed by Aguilera et al., 2009). Recently, it has been shown that the secretion machinery is located at the bacterial poles during infection (Morgan et al., 2010).

Phase I C. burnetii triggers tumour necrosis factor (TNF) synthesis by infected monocytes (Capo et al., 1996). It has been suggested that the increased TNF may induce expression of the receptors on the macrophage surface, and thus facilitate uptake, which is relatively inefficient (Mege et al., 1997). Somewhat at odds with this, it has also been found that TNF, in conjunction with gamma interferon (IFN- $\gamma)$, results in the killing of C. burnetii in THP-1 monocytes by an apoptotic mechanism (Dellacasagrande et al., 1999). However, although IFN- $\gamma$ is key to controlling Q fever (Scott et al., 1987), apoptosis is closely controlled by the invading Coxiella to maintain viability of the host cell during the lengthy inhabitation (Voth et al., 2007). Infected host cells show decreased caspase activity, induction of a pro-survival transcriptional response, including Akt and Erk 1/2 activation, and decreased release of cytochrome c (Voth et al., 2007, 2009; Lührmann \& Roy, 2007). In addition to controlling apoptosis, C. burnetii modulates autophagy (Gutierrez et al., 2005). The autophagy pathway protein Bectin 1 and the anti-apoptotic protein $\mathrm{Bcl} 1$ are both recruited to the membrane of the vacuole surrounding the Coxiella (Vázquez \& Colombo, 2010b) and interplay of these proteins is essential for successful infection to be established (Vázquez \& Colombo, 2010b), and for correct modulation of both apoptosis and autophagy (Vázquez \& Colombo, 2010a).

The immune response to chronic infection is different to that observed in acute infection. For example, peripheral blood lymphocytes from chronically infected individuals do not proliferate when exposed to C. burnetii antigens (although they retain the ability to proliferate when exposed to other antigens and mitogens) (Koster et al., $1985 b$ ), whereas a response is seen in people recovering from acute Q fever or in vaccinees (Izzo et al., 1988; Koster et al., 1985a). Interestingly, C. burnetii phase I cells expressing full-length LPS appear almost invisible to dendritic cells (Shannon et al., 2005), which may be a key factor in the development of chronic infections.

Cell-mediated immune responses are key to controlling Q fever, but the role of humoral responses is not clear. For a range of intracellular pathogens it has been shown that both cell-mediated and humoral responses are required to defend against intracellular pathogens (Casadevall \& Pirofski, 2006). During primary acute Q fever, antibodies are key during the bacteraemic phase of acute infection, but are potentially detrimental during chronic infection, where immune complexes can cause pathology (Raoult, 1990). Passive transfer of antibody has been shown to be able to protect animals against subsequent challenge with C. burnetii (Burnet \& Freeman, 1983), although no protection was seen if antibody was transferred to SCID mice, showing the importance of the cell-mediated response (Zhang et al., 2007). Opsonization resulted in increased uptake in vitro by macrophages and dendritic cells, but did not subsequently impact on growth intracellularly (Shannon et al., 2009).

\section{Vaccines}

Ever since the discovery of the aetiological agent of $\mathrm{Q}$ fever, there have been attempts to produce a safe, effective vaccine. However, only partial success has been achieved, as will be discussed. Four main vaccines have been used in 
humans: a live attenuated strain, M-44; a trichloroacetic acid (TCA) extract; a chloroform-methanol extract; a formalin-inactivated culture extract.

The live attenuated strain designated M-44 was isolated in the former Soviet Union in the 1960s. This was obtained by repeated passage through guinea pigs and mice. In human volunteers, minimal side effects were reported, but issues with long-term persistence in animals raised concerns about safety, including the risk of endocarditis developing in recipients (Freylikhman et al., 2003; Marmion, 1967). Therefore, despite extensive use in Russia, this strain is not used in the West.

Due to the issues identified with persistence of live attenuated strains, various approaches were examined for developing inert vaccines. Generally attention has focussed on the phase I micro-organisms, as these are significantly more effective than the phase II form (Ormsbee et al., 1964). The chloroform-methanol residue (CMR) vaccine was developed in the USA (Fries et al., 1993). Based on the phase I Henzerling strain of C. burnetii, it was able to induce protection in animals, including primates exposed to aerosol challenge (Fries et al., 1993; Waag et al., 2002). However, on transition into human volunteer studies the CMR vaccine was found to be overly reactogenic (Fries et al., 1993). Similarly, a soluble TCA extract of phase I Nine Mile strain, containing proteins and LPS, was highly reactogenic in humans (Kazár et al., 1982), and combining TCA and CMR approaches, although producing a less reactive vaccine, resulted in loss of immunogenicity (Kazár et al., 1987).

A formalin-inactivated vaccine prepared by Commonwealth Serum Laboratories named Q-Vax is licensed for use in Australia. The vaccine is prepared from the phase I Henzerling strain. Studies have reported $100 \%$ efficacy in abattoir workers for many years post-vaccination (Ackland et al., 1994; Marmion et al., 1990). However, similarly to the CMR and TCA extract vaccines, Q-Vax induced side-effects in a significant proportion of recipients. The most common adverse reactions reported involved swelling, erythema and tenderness at the site of inoculation, but headaches and flulike symptoms were reported in up to $18 \%$ of recipients. Individuals who are sero-positive prior to immunization can suffer severe reactions (Bell et al., 1964), and as such should be identified with a pre-vaccination skin-test (Ascher et al., 1983), and for the same reason a single-dose regimen is recommended (Ormsbee \& Marmion, 1990).

As a result of the safety considerations regarding immunization with Q-Vax, there is a need to identify an improved vaccine for $Q$ fever; however, there is a significantly lower effort on this than for other bioweapon pathogens, such as anthrax and plague. Recombinant protein subunit vaccines expressed in E. coli have shown limited efficacy. However, immunization with identical native proteins isolated directly from C. burnetii did result in reduced microbial colonization in non-lethal animal models (Table 2). Two reasons for this discrepancy have been suggested: either post-translational modification in C. burnetii results in different antigenicity compared to protein expression in E. coli, or the proteins were contaminated with LPS (Shannon \& Heinzen, 2009). It is known that LPS purified from phase I organisms can induce protective immune responses in animals (Zhang et al., 2007).

\section{Is C. burnetii a real biological threat?}

When considering microbes as weapons they can simplistically be divided into lethal agents and incapacitating agents. Lethal agents, such as Yersinia pestis, induce an acute disease with a high associated mortality rate. Incapacitating agents make people ill enough that they cannot carry on with normal life for a period of time, but ultimately most people will recover. Q fever belongs primarily to the incapacitating agents. It is considered that a biological attack will affect the largest number of people if disseminated as an aerosol. Q fever has been shown to travel over large distances on the

Table 2. Studies of recombinant and native protein subunits of $C$. burnetii

\begin{tabular}{|c|c|c|c|}
\hline Antigen & Source & Result & Reference \\
\hline Heat-shock protein B (HspB) & Recombinant expression in E. coli & No protection & Li et al. (2005) \\
\hline $29 \mathrm{kDa}$ outer-membrane protein (P1) & Recombinant expression in E. coli & No protection & Li et al. (2005) \\
\hline $\mathrm{P} 1$ & C. burnetii Phase I Nine Mile & $\begin{array}{l}\text { Reduced splenic colonization in } \\
\text { mice following challenge }\end{array}$ & Williams et al. (1990) \\
\hline P1 & Recombinant expression in E. coli & No protection & Zhang \& Samuel (2003) \\
\hline $\begin{array}{l}\text { Omp, Pmm, HspB, Fbp, Orf 410, Crc, } \\
\text { CbMip, MucZ }\end{array}$ & Recombinant expression in E. coli & No protection & Tyczka et al. (2005) \\
\hline Com & Recombinant expression in E. coli & No protection & Zhang \& Samuel (2003) \\
\hline CbMip & Recombinant expression in E. coli & No protection & Zhang \& Samuel (2003) \\
\hline P28 & Recombinant expression in E. coli & No protection & Zhang \& Samuel (2003) \\
\hline P1-HspB fusion & Recombinant expression in E. coli & $\begin{array}{l}\text { Reduced splenic colonization in } \\
\text { mice following challenge }\end{array}$ & Li et al. (2005) \\
\hline $67 \mathrm{kDa}$ outer-membrane protein & C. burnetii QiYi & $\begin{array}{l}\text { Protection observed in mice and } \\
\text { guinea pigs }\end{array}$ & Zhang et al. (1994) \\
\hline
\end{tabular}


wind during natural outbreaks, and is a relatively resistant organism in the environment. In addition, as described above, the infectious dose for man is extremely low. For this reason, the pathogen attracted attention in offensive programmes of the last century. However, a significant impediment to use of C. burnetii is the difficulty in culturing the pathogen. As mentioned previously, the WHO modelled the effects of a release of $50 \mathrm{~kg} \mathrm{C}$. burnetii over an urban area. However, a typical yield of Coxiella reported in the literature is around $1 \mathrm{~g}$ wet weight organism from eight dozen eggs (Baca \& Paretsky, 1983).

The zoonotic nature of $\mathrm{Q}$ fever is a problem for defence. $\mathrm{Q}$ fever outbreaks occur throughout the world, and the symptoms are vague and non-specific. To this end, it would be difficult to identify a small-scale deliberate release. For example, during Desert Storm, 19 deployed US troops were hospitalized with acute bilateral pneumonitis in March 2003. However, only one of these was subsequently confirmed as a $\mathrm{Q}$ fever case, which was probably acquired enzootically (Mitchell et al., 2007).

However, routine health surveillance would identify a peak in cases, which would not be the normal pattern in endemic areas. An attack would also have implications for agriculture, as infection would occur in both wild and domesticated animals. This could result in secondary cases of infection in man. The post-release sequelae, including on epidemiology, have been discussed in depth by Madariaga et al. (2003). As with any biothreat agent, the consequences of use would be significant, but are further complicated for C. burnetii by its environmental stability and resistance to chemical decontaminants.

\section{References}

Ackland, J. R., Worswick, D. A. \& Marmion, B. P. (1994). Vaccine prophylaxis of Q fever - a follow-up study of the efficacy of Q-Vax (CSL) 1985-1990. Med J Aust 160, 704-708.

Aguilera, M., Salinas, R., Rosales, E., Carminati, S., Colombo, M. I. \& Berón, W. (2009). Actin dynamics and Rho GTPases regulate the size and formation of parasitophorous vacuoles containing Coxiella burnetii. Infect Immun 77, 4609-4620.

Akporiaye, E. T. \& Baca, O. G. (1983). Superoxide anion production and superoxide dismutase and catalase activities in Coxiella burnetii. $J$ Bacteriol 154, 520-523.

Angelakis, E. \& Raoult, D. (2010). Q fever. Vet Microbiol 140, 297 309.

Ascher, M. S., Berman, M. A. \& Ruppanner, R. (1983). Initial clinical and immunological evaluation of a new phase I Q fever vaccine and skin test in humans. J Infect Dis 148, 214-222.

Astobiza, I., Barandika, J. F., Hurtado, A., Juste, R. A. \& Garcia-Perez, A. L. (2010). Kinetics of Coxiella burnetii excretion in a commercial dairy sheep flock after treatment with oxytetracycline. Vet J 184, 172175.

Atzpodien, E., Baumgartner, W., Artelt, A. \& Thiele, D. (1994). Valvular endocarditis occurs as a part of a disseminated Coxiella burnetii infection in immunocompromised $\mathrm{BALB} / \mathrm{cJ}\left(\mathrm{H}-2^{\mathrm{d}}\right)$ mice infected with the Nine Mile isolate of Coxiella burnetii. J Infect Dis 170, 223-226.
Ayres, J. G., Smith, E. G. \& Flint, N. (1996). Protracted fatigue and debility after acute Q fever. Lancet 347, 978-979.

Ayres, J. G., Flint, N., Smith, E. G., Tunnicliffe, W. S., Fletcher, T. J., Hammond, K., Ward, D. \& Marmion, B. P. (1998). Post-infection fatigue syndrome following Q fever. QJM 91, 105-123.

Babudieri, B. (1959). Q fever: a zoonosis. Adv Vet Sci 5, 81-154.

Baca, O. G. \& Paretsky, D. (1983). Q fever and Coxiella burnetii: a model for host-parasite interactions. Microbiol Rev 47, 127-149.

Baca, O. G., Klassen, D. A. \& Aragon, A. S. (1993). Entry of Coxiella burnetii into host cells. Acta Virol 37, 143-155.

Beare, P. A., Howe, D., Cockrell, D. C., Omsland, A., Hansen, B. \& Heinzen, R. A. (2009a). Characterization of a Coxiella burnetii fts $Z$ mutant generated by Himar1 transposon mutagenesis. J Bacteriol 191, 1369-1381.

Beare, P. A., Unsworth, N., Andoh, M., Voth, D. E., Omsland, A., Gilk, S. D., Williams, K. P., Sobral, B. W., Kupko, J. J., III \& other authors (2009b). Comparative genomics reveal extensive transposonmediated genomic plasticity and diversity among potential effector proteins within the genus Coxiella. Infect Immun 77, 642-656.

Bell, J. F., Lackman, D. B., Meis, A. \& Hadlow, W. J. (1964). Recurrent reaction at site of $\mathrm{Q}$ fever vaccination in a sensitized person. Mil Med 129, 591.

Berón, W., Gutierrez, M. G., Rabinovitch, M. \& Colombo, M. I. (2002). Coxiella burnetii localizes in a Rab7-labeled compartment with autophagic characteristics. Infect Immun 70, 5816-5821.

Burnet, F. M. \& Freeman, M. (1937). Experimental studies on the virus of Q fever. Med J Aust 2, 299-302.

Burnet, F. M. \& Freeman, M. (1983). Experimental studies on the virus of "Q" fever (reprinted). Rev Infect Dis 5, 800-808.

Capo, C., Zugun, F., Stein, A., Tardei, G., Lepidi, H., Raoult, D. \& Mege, J. L. (1996). Upregulation of tumor necrosis factor alpha and interleukin-1 beta in Q fever endocarditis. Infect Immun 64, 16381642.

Capo, C., Moynault, A., Collette, Y., Olive, D., Brown, E. J., Raoult, D. \& Mege, J. L. (2003). Coxiella burnetii avoids macrophage phagocytosis by interfering with spatial distribution of complement receptor 3. J Immunol 170, 4217-4225.

Casadevall, A. \& Pirofski, L. A. (2006). A reappraisal of humoral immunity based on mechanisms of antibody-mediated protection against intracellular pathogens. Adv Immunol 91, 1-44.

Chen, S. Y., Vodkin, M., Thompson, H. A. \& Williams, J. C. (1990). Isolated Coxiella burnetii synthesizes DNA during acid activation in the absence of host cells. J Gen Microbiol 136, 89-96.

Cockrell, D. C., Beare, P. A., Fischer, E. R., Howe, D. \& Heinzen, R. A. (2008). A method for purifying obligate intracellular Coxiella burnetii that employs digitonin lysis of host cells. J Microbiol Methods 72, 321325.

Coleman, S. A., Fischer, E. R., Howe, D., Mead, D. J. \& Heinzen, R. A. (2004). Temporal analysis of Coxiella burnetii morphological differentiation. J Bacteriol 186, 7344-7352.

Cox, H. R. \& Bell, E. J. (1939). The cultivation of Rickettsia diaporica in tissue culture and in the tissues of developing chick embryos. Public Health Rep 54, 2171-2178.

Davis, G. E. \& Cox, H. R. (1938). A filter-passing infectious agent isolated from ticks. I. Isolation from Dermacentor andersoni, reactions in animals, and filtration experiments. Public Health Rep 53, 22592282.

Davis, J. L. \& Patrick, W. C. (1965). New method for purifying Coxiella burnetii by dextran sulfate precipitation followed by centrifugation. Appl Microbiol 13, 99. 
Dellacasagrande, J., Capo, C., Raoult, D. \& Mege, J. L. (1999). IFN- $\gamma-$ mediated control of Coxiella burnetii survival in monocytes: the role of cell apoptosis and TNF. J Immunol 162, 2259-2265.

Denison, A. M., Massung, R. F. \& Thompson, H. A. (2007). Analysis of the O-antigen biosynthesis regions of phase II Isolates of Coxiella burnetii. FEMS Microbiol Lett 267, 102-107.

Derrick, E. H. (1937). "Q" fever, a new fever entity: clinical features, diagnosis and laboratory investigation. Med J Aust 2, 281-299.

Dupuis, G., Petite, J., Peter, O. \& Vouilloz, M. (1987). An important outbreak of human $\mathrm{Q}$ fever in a Swiss alpine valley. Int J Epidemiol 16, 282-287.

Enserink, M. (2010). Questions abound in Q-fever explosion in the Netherlands. Science 327, 266-267.

Felsheim, R. F., Herron, M. J., Nelson, C. M., Burkhardt, N. Y., Barbet, A. F., Kurtti, T. J. \& Munderloh, U. G. (2006). Transformation of Anaplasma phagocytophilum. BMC Biotechnol 6, 42.

Fenollar, F. \& Raoult, D. (2007). Molecular diagnosis of bloodstream infections caused by non-cultivable bacteria. Int J Antimicrob Agents 30, S7-S15.

Fenollar, F., Fournier, P. E. \& Raoult, D. (2004). Molecular detection of Coxiella burnetti in the sera of patients with $Q$ fever endocarditis or vascular infection. J Clin Microbiol 42, 4919-4924.

Fernández-Guerrero, M. L., Muelas, J. M., Aguado, J. M., Renedo, G., Fraile, J., Soriano, F. \& De Villalobos, E. (1988). Q fever endocarditis on porcine bioprosthetic valves. Clinicopathologic features and microbiologic findings in 3 patients treated with doxycycline, cotrimoxazole, and valve-replacement. Ann Intern Med 108, 209-213.

Fiset, P. (1957). Phase variation of Rickettsia (Coxiella) burnetii; study of the antibody response in guinea pigs and rabbits. Can J Microbiol 3, 435-445.

Fishbein, D. B. \& Raoult, D. (1992). A cluster of Coxiella burnetii infections associated with exposure to vaccinated goats and their unpasteurized dairy products. Am J Trop Med Hyg 47, 35-40.

Fitzpatrick, K. A., Kersh, G. J. \& Massung, R. F. (2010). Practical method for extraction of PCR-quality DNA from environmental soil samples. Appl Environ Microbiol 76, 4571-4573.

Franco, I. S., Shuman, H. A. \& Charpentier, X. (2009). The perplexing functions and surprising origins of Legionella pneumophila type IV secretion effectors. Cell Microbiol 11, 1435-1443.

Freylikhman, O., Tokarevich, N., Suvorov, A., Vorobiova, E. \& Totolian, A. (2003). Coxiella burnetti persistence in three generations of mice after application of live attenuated human M-44 vaccine against Q fever. Ann N Y Acad Sci 990, 496-499.

Fries, L. F., Waag, D. M. \& Williams, J. C. (1993). Safety and immunogenicity in human volunteers of a chloroform-methanol residue vaccine for Q fever. Infect Immun 61, 1251-1258.

Gami, A. S., Antonios, V. S., Thompson, R. L., Chaliki, H. P. \& Ammash, N. M. (2004). Q fever endocarditis in the United States. Mayo Clin Proc 79, 253-257.

Gimenez, D. F. (1964). Staining rickettsiae in yolk-sac cultures. Stain Technol 39, 135-140.

Gonder, J. C., Kishimoto, R. A., Kastello, M. D., Pedersen, C. E. \& Larson, E. W. (1979). Cynomolgus monkey model for experimental Q fever infection. J Infect Dis 139, 191-196.

Gutierrez, M. G., Vázquez, C. L., Munafo, D. B., Zoppino, F. C. M., Berón, W., Rabinovitch, M. \& Colombo, M. I. (2005). Autophagy induction favours the generation and maturation of the Coxiellareplicative vacuoles. Cell Microbiol 7, 981-993.

Hacker, J. \& Fischer, G. (1993). Immunophilins: structure-function relationship and possible role in microbial pathogenicity. Mol Microbiol 10, 445-456.
Hackstadt, T. (1990). The role of lipopolysaccharides in the virulence of Coxiella burnetii. Ann N Y Acad Sci 590, 27-32.

Hackstadt, T. \& Williams, J. C. (1981). Biochemical stratagem for obligate parasitism of eukaryotic cells by Coxiella burnetii. Proc Natl Acad Sci U S A 78, 3240-3244.

Hackstadt, T. \& Williams, J. C. (1983). pH-dependence of the Coxiella burnetii glutamate transport system. J Bacteriol 154, 598-603.

Hackstadt, T., Peacock, M. G., Hitchcock, P. J. \& Cole, R. L. (1985). Lipopolysaccharide variation in Coxiella burnetii: intrastrain heterogeneity in structure and antigenicity. Infect Immun 48, 359-365.

Heinzen, R. A., Scidmore, M. A., Rockey, D. D. \& Hackstadt, T. (1996). Differential interaction with endocytic and exocytic pathways distinguish parasitophorous vacuoles of Coxiella burnetii and Chlamydia trachomatis. Infect Immun 64, 796-809.

Heinzen, R. A., Hackstadt, T. \& Samuel, J. E. (1999). Developmental biology of Coxiella burnetii. Trends Microbiol 7, 149-154.

Hendrix, L. \& Mallavia, L. P. (1984). Active transport of proline by Coxiella burnetii. J Gen Microbiol 130, 2857-2863.

Hilbink, F., Penrose, M., Kovácová, E. \& Kazár, J. (1993). Q fever is absent from New Zealand. Int J Epidemiol 22, 945-949.

Honstettre, A., Ghigo, E., Moynault, A., Capo, C., Toman, R., Akira, S., Takeuchi, O., Lepidi, H., Raoult, D. \& Mege, J. L. (2004). Lipopolysaccharide from Coxiella burnetii is involved in bacterial phagocytosis, filamentous actin reorganization, and inflammatory responses through Toll-like receptor 4. J Immunol 172, 3695-3703.

Hoover, T. A., Culp, D. W., Vodkin, M. H., Williams, J. C. \& Thompson, H. A. (2002). Chromosomal DNA deletions explain phenotypic characteristics of two antigenic variants, phase II and RSA 514 (Crazy), of the Coxiella burnetii Nine Mile strain. Infect Immun 70, 6726-6733.

Howe, D. \& Mallavia, L. P. (2000). Coxiella burnetti exhibits morphological change and delays phagolysosomal fusion after internalization by J774A.1 cells. Infect Immun 68, 3815-3821.

Howe, D., Shannon, J. G., Winfree, S., Dorward, D. W. \& Heinzen, R. A. (2010). Coxiella burnetii phase I and II variants replicate with similar kinetics in degradative phagolysosome-like compartments of human macrophages. Infect Immun 78, 3465-3474.

Izzo, A. A., Marmion, B. P. \& Worswick, D. A. (1988). Markers of cellmediated immunity after vaccination with an inactivated, whole-cell Q fever vaccine. J Infect Dis 157, 781-789.

Jäger, C., Lautenschläger, S., Willems, H. \& Baljer, G. (2002). Coxiella burnetii plasmid types QpDG and QpH1 are closely related and likely identical. Vet Microbiol 89, 161-166.

Kazár, J. (1996). Q fever. In Rickettsiae and Rickettsial Diseases, pp. 353-362. Edited by J. Kazár \& R. Toman. Bratislava: Slovak Academy of Sciences.

Kazár, J., Brezina, R., Palanová, A., Tvrdá, B. \& Schramek, S. (1982). Immunogenicity and reactogenicity of a $Q$ fever chemovaccine in persons professionally exposed to Q fever in Czechoslovakia. Bull World Health Organ 60, 389-394.

Kazár, J., Schramek, S., Lisák, V. \& Brezina, R. (1987). Antigenicity of chloroform-methanol-treated Coxiella burnetii preparations. Acta Virol 31, 158-167.

Kersh, G. J., Wolfe, T. M., Fitzpatrick, K. A., Candee, A. J., Oliver, L. D., Patterson, N. E., Self, J. S., Priestley, R. A., Loftis, A. D. \& Massung, R. F. (2010). Presence of Coxiella burnetii DNA in the environment of the United States, 2006 to 2008. Appl Environ Microbiol 76, 44694475.

Kishimoto, R. A., Rozmiarek, H. \& Larson, E. W. (1978). Experimental $\mathrm{Q}$ fever infection in congenitally athymic nude mice. Infect Immun 22, 69-71. 
Klee, S. R., Ellerbrok, H., Tyczka, J., Franz, T. \& Appel, B. (2006). Evaluation of a real-time PCR assay to detect Coxiella burnetii. Ann N Y Acad Sci 1078, 563-565.

Koster, F. T., Williams, J. C. \& Goodwin, J. S. (1985a). Cellular immunity in $\mathrm{Q}$ fever - modulation of responsiveness by a suppressor T cell-monocyte circuit. J Immunol 135, 1067-1072.

Koster, F. T., Williams, J. C. \& Goodwin, J. S. (1985b). Cellular immunity in Q fever: specific lymphocyte unresponsiveness in Q fever endocarditis. J Infect Dis 152, 1283-1289.

Kovácová, E. \& Kazár, J. (2002). Q fever - still a query and underestimated infectious disease. Acta Virol 46, 193-210.

Kristinsson, A. \& Bentall, H. H. (1967). Medical and surgical treatment of Q-fever endocarditis. Lancet 290, 693-697.

La Scola, B., Lepidi, H. \& Raoult, D. (1997). Pathologic changes during acute $\mathrm{Q}$ fever: influence of the route of infection and inoculum size in infected guinea pigs. Infect Immun 65, 2443-2447.

Lautenschläger, S., Willems, H., Jäger, C. \& Baljer, G. (2000). Sequencing and characterization of the cryptic plasmid QpRS from Coxiella burnetii. Plasmid 44, 85-88.

Levy, P. Y., Drancourt, M., Etienne, J., Auvergnat, J. C., Beytout, J., Sainty, J. M., Goldstein, F. \& Raoult, D. (1991). Comparison of different antibiotic regimens for therapy of 32 cases of $Q$ fever endocarditis. Antimicrob Agents Chemother 35, 533-537.

Li, Q., Niu, D., Wen, B., Chen, M., Qiu, L. \& Zhang, J. (2005). Protective immunity against $\mathrm{Q}$ fever induced with a recombinant P1 antigen fused with HspB of Coxiella burnetii. Ann N Y Acad Sci 1063, 130142.

Liu, Z. M., Tucker, A. M., Driskell, L. O. \& Wood, D. O. (2007). Mariner-based transposon mutagenesis of Rickettsia prowazekii. Appl Environ Microbiol 73, 6644-6649.

Lührmann, A. \& Roy, C. R. (2007). Coxiella bumetii inhibits activation of host cell apoptosis through a mechanism that involves preventing cytochrome c release from mitochondria. Infect Immun 75, 52825289

Madariaga, M. G., Rezai, K., Trenholme, G. M. \& Weinstein, R. A. (2003). Q fever: a biological weapon in your backyard. Lancet Infect Dis 3, 709-721.

Mallavia, L. P. (1991). Genetics of Rickettsiae. Eur J Epidemiol 7, $213-$ 221.

Marmion, B. P. (1967). Development of Q-fever vaccines, 1937 to 1967. Med J Aust 2, 1074-1078.

Marmion, B. P., Ormsbee, R. A., Kyrkou, M., Wright, J., Worswick, D. A., Izzo, A. A., Esterman, A., Feery, B. \& Shapiro, R. A. (1990). Vaccine prophylaxis of abattoir-associated Q fever: 8 years' experience in Australian abattoirs. Epidemiol Infect 104, 275-287.

Marmion, B. P., Shannon, M., Maddocks, I., Storm, P. \& Penttila, I. (1996). Protracted debility and fatigue after acute Q fever. Lancet 347, 977-978.

Marmion, B. P., Sukocheva, O., Storm, P. A., Lockhart, M., Turra, M., Kok, T., Ayres, J., Routledge, H. \& Graves, S. (2009). Q fever: persistence of antigenic non-viable cell residues of Coxiella burnetii in the host - implications for post Q fever infection fatigue syndrome and other chronic sequelae. QJM 102, 673-684.

Marrie, T. J., Van Buren, J., Fraser, J., Haldane, E. V., Faulkner, R. S. Williams, J. C. \& Kwan, C. (1985). Seroepidemiology of Q fever among domestic animals in Nova Scotia. Am J Public Health 75, 763-766.

Marrie, T. J., Stein, A., Janigan, D. \& Raoult, D. (1996). Route of infection determines the clinical manifestations of acute $Q$ fever. J Infect Dis 173, 484-487.

Maurin, M. \& Raoult, D. (1999). Q fever. Clin Microbiol Rev 12, 518553.
McCaul, T. F. (1991). The developmental cycle of Coxiella burnetii. In Q Fever: The Biology of Coxiella burnetii, pp. 223-258. Edited by J. C. Williams \& H. A. Thompson. Boca Raton, FL: CRC Press.

McCaul, T. F. \& Williams, J. C. (1981). Developmental cycle of Coxiella burnetii: structure and morphogenesis of vegetative and sporogenic differentiations. J Bacteriol 147, 1063-1076.

McCaul, T. F., Williams, J. C. \& Thompson, H. A. (1991). Electron microscopy of Coxiella burnetii in tissue culture. Induction of cell types as products of developmental cycle. Acta Virol 35, 545-556.

Mege, J. L., Maurin, M., Capo, C. \& Raoult, D. (1997). Coxiella burnetii: the 'query' fever bacterium. A model of immune subversion by a strictly intracellular microorganism. FEMS Microbiol Rev 19, 209217.

Meghari, S., Bechah, Y., Capo, C., Lepidi, H., Raoult, D., Murray, P. J. \& Mege, J. L. (2008). Persistent Coxiella burnetii infection in mice overexpressing IL-10: an efficient model for chronic Q fever pathogenesis. PLoS Pathog 4, e23.

Miceli, M. H., Veryser, A. K., Anderson, A. D., Hofinger, D., Lee, S. A. \& Tancik, C. (2010). A case of person-to-person transmission of Q fever from an active duty service to his spouse. Vector Borne Zoonotic Dis 10, 539-541.

Milazzo, A., Hall, R., Storm, P. A., Harris, R. J., Winslow, W. \& Marmion, B. P. (2001). Sexually transmitted Q fever. Clin Infect Dis 33, 399-402.

Mitchell, A. E., Sivitz, L. B. \& Black, R. E. (2007). Infectious diseases diagnosed in US troops who served in the Persian Gulf War, Operation Enduring Freedom, or Operation Iraqi Freedom. In Gulf War and Health, vol. 5, Infectious Diseases, pp. 61-94. Washington, DC: The National Academies Press.

Mo, Y. Y., Cianciotto, N. P. \& Mallavia, L. P. (1995). Molecular cloning of a Coxiella burnetii gene encoding a macrophage infectivity potentiator (Mip) analog. Microbiology 141, 2861-2871.

Morgan, J. K., Luedtke, B. E. \& Shaw, E. I. (2010). Coxiella burnetii type IVB secretion system region I genes are expressed early during the infection of host cells. FEMS Microbiol Lett 305, 177-183.

Ninio, S. \& Roy, C. R. (2007). Effector proteins translocated by Legionella pneumophila: strength in numbers. Trends Microbiol 15, 372-380.

Olson, J. G., Jones, F. R. \& Blair, P. J. (2006). Rickettsia spp. In Principles and Practice of Clinical Bacteriology, pp. 285-294. Edited by S. H. Gillespie \& P. M. Hawkey. Chichester, UK: Wiley.

Omsland, A., Cockrell, D. C., Howe, D., Fischer, E. R., Virtaneva, K., Sturdevant, D. E., Porcella, S. F. \& Heinzen, R. A. (2009). Host cellfree growth of the $\mathrm{Q}$ fever bacterium Coxiella burnetii. Proc Natl Acad Sci U S A 106, 4430-4434.

Ormsbee, R. A. (1962). A method of purifying Coxiella burnetii and other pathogenic rickettsiae. J Immunol 88, 100-108.

Ormsbee, R. A. \& Marmion, B. P. (1990). Prevention of Coxiella burnetii infection: vaccines and guidelines for those at risk. In $Q$ Fever, vol. 1, The Disease, pp. 225-248. Edited by T. J. Marrie. Boca Raton, FL: CRC Press.

Ormsbee, R. A., Bell, E. J., Tallent, G. \& Lackman, D. B. (1964). Influence of phase on protective potency of $\mathrm{Q}$ fever vaccine. J Immunol 92, 404.

Palmer, N. C., Kierstead, M., Key, D. W., Williams, J. C., Peacock, M. G. \& Vellend, H. (1983). Placentitis and abortion in goats and sheep in Ontario caused by Coxiella burnetii. Can Vet J 24, 60-61.

Parkhill, J., Wren, B. W., Thomson, N. R., Titball, R. W., Holden, M. T., Prentice, M. B., Sebaihia, M., James, K. D., Churcher, C. \& other authors (2001). Genome sequence of Yersinia pestis, the causative agent of plague. Nature 413, 523-527. 
Pittman, P. R., Norris, S. L., Coonan, K. M. \& Mckee, K. T. (2005). An assessment of health status among medical research volunteers who served in the Project Whitecoat program at Fort Detrick, Maryland. Mil Med 170, 183-187.

Rady, M., Glavits, R. \& Nagy, G. (1985). Isolation of Coxiella burnetii and diagnosis of the Q-fever associated abortion in cows and ewes in Hungary. Magyar Allatorvosok Lapja 40, 343-349.

Raoult, D. (1990). Host factors in the severity of Q fever. Ann NY Acad Sci 590, 33-38.

Raoult, D. (2009). Reemergence of Q fever after 11 September 2001. Clin Infect Dis 48, 558-559.

Redd, T. \& Thompson, H. A. (1995). Secretion of proteins by Coxiella burnetii. Microbiology 141, 363-369.

Romano, P. S., Gutierrez, M. G., Berón, W., Rabinovitch, M. \& Colombo, M. I. (2007). The autophagic pathway is actively modulated by phase II Coxiella burnetii to efficiently replicate in the host cell. Cell Microbiol 9, 891-909.

Russell-Lodrigue, K. E., Zhang, G. Q., McMurray, D. N. \& Samuel, J. E. (2006). Clinical and pathologic changes in a guinea pig aerosol challenge model of acute Q fever. Infect Immun 74, 6085-6091.

Samuel, J. E., Frazier, M. E., Kahn, M. L., Thomashow, L. S. \& Mallavia, L. P. (1983). Isolation and characterization of a plasmid from phase I Coxiella burnetii. Infect Immun 41, 488-493.

Savinelli, E. A. \& Mallavia, L. P. (1990). Comparison of Coxiella burnetii plasmids to homologous chromosomal sequences present in a plasmidless endocarditis-causing isolate. Ann N Y Acad Sci 590, 523533.

Schneeberger, P. M., Hermans, M. H. A., van Hannen, E. J., Schellekens, J. J. A., Leenders, A. C. A. P. \& Wever, P. C. (2010). Real-time PCR with serum samples is indispensable for early diagnosis of acute Q fever. Clin Vaccine Immunol 17, 286-290.

Schramek, S. \& Mayer, H. (1982). Different sugar compositions of lipopolysaccharides isolated from phase I and pure phase II cells of Coxiella burnetii. Infect Immun 38, 53-57.

Scott, G. H. \& Williams, J. C. (1990). Susceptibility of Coxiella burnetii to chemical disinfectants. Ann N Y Acad Sci 590, 291-296.

Scott, G. H., Williams, J. C. \& Stephenson, E. H. (1987). Animal models in Q fever: pathological responses of inbred mice to phase I Coxiella burnetii. J Gen Microbiol 133, 691-700.

Seshadri, R., Paulsen, I. T., Eisen, J. A., Read, T. D., Nelson, K. E., Nelson, W. C., Ward, N. L., Tettelin, H., Davidsen, T. M. \& other authors (2003). Complete genome sequence of the Q-fever pathogen Coxiella burnetii. Proc Natl Acad Sci U S A 100, 5455-5460.

Shannon, J. G. \& Heinzen, R. A. (2009). Adaptive immunity to the obligate intracellular pathogen Coxiella burnetii. Immunol Res 43, 138-148.

Shannon, J. G., Howe, D. \& Heinzen, R. A. (2005). Virulent Coxiella burnetii does not activate human dendritic cells: role of lipopolysaccharide as a shielding molecule. Proc Natl Acad Sci U S A 102, 8722-8727.

Shannon, J. G., Cockrell, D. C., Takahashi, K., Stahl, G. L. \& Heinzen, R. A. (2009). Antibody-mediated immunity to the obligate intracellular bacterial pathogen Coxiella burnetii is Fc receptor- and complement-independent. BMC Immunol 10, 26.

Sidwell, R. W., Gebhardt, L. P. \& Thorpe, B. D. (1964a). Studies of latent $\mathrm{Q}$ fever infections. 2. Effects of multiple cortisone injections. Am J Hyg 79, 320.

Sidwell, R. W., Gebhardt, L. P. \& Thorpe, B. D. (1964b). Studies of latent Q fever infections. I. Effects of whole body X-irradiation upon latently infected guinea pigs, white mice and deer mice. Am J Hyg 79, 113.
Smith, D. J. W. (1940). Studies on the epidemiology of Q fever. III. The transmission of Q fever by the tick Haemaphysalis humerosa. Aust J Exp Biol Med Sci 18, 103-106.

Smith, D. J. W. (1941). Studies on the epidemiology of Q fever. VIII. The transmission of $\mathrm{Q}$ fever by the tick Rhipicephalus sanguineus. Aust J Exp Biol Med Sci 19, 119-122.

Stein, A. \& Raoult, D. (1999). Pigeon pneumonia in Provence: a birdborne Q fever outbreak. Clin Infect Dis 29, 617-620.

Stein, A., Lepidi, H., Mege, J. L., Marrie, T. J. \& Raoult, D. (2000). Repeated pregnancies in BALB/c mice infected with Coxiella burnetii cause disseminated infection, resulting in stillbirth and endocarditis. J Infect Dis 181, 188-194.

Suhan, M., Chen, S. Y., Thompson, H. A., Hoover, T. A., Hill, A. \& Williams, J. C. (1994). Cloning and characterization of an autonomous replication sequence from Coxiella burnetii. J Bacteriol 176, 52335243.

Tigertt, W. D., Benenson, A. S. \& Gochenour, W. S. (1961). Airborne Q fever. Bacteriol Rev 25, 285.

Tissot Dupont, H., Raoult, D., Brouqui, P., Janbon, F., Peyramond, D., Weiller, P.-J., Chicheportiche, C., Nezeri, M. \& Poirier, R. (1992). Epidemiologic features and clinical presentation of acute $\mathrm{Q}$ fever in hospitalized patients: 323 French cases. Am J Med 93, 427-434.

To, H., Htwe, K. K., Kako, N., Kim, H. J., Yamaguchi, T., Fukushi, H. \& Hirai, K. (1998). Prevalence of Coxiella burnetii infection in dairy cattle with reproductive disorders. J Vet Med Sci 60, 859-861.

Tyczka, J., Eberling, S. \& Balfer, G. (2005). Immunization experiments with recombinant Coxiella burnetii proteins in a murine infection model. Ann N Y Acad Sci 1063, 143-148.

Valková, D. \& Kazár, J. (1995). A new plasmid (Qpdv) common to Coxiella burnetti isolates associated with acute and chronic Q fever. FEMS Microbiol Lett 125, 275-280.

Vázquez, C. L. \& Colombo, M. I. (2010a). Beclin 1 modulates the antiapoptotic activity of Bcl-2: insights from a pathogen infection system. Autophagy 6, 177-178.

Vázquez, C. L. \& Colombo, M. I. (2010b). Coxiella burnetii modulates Beclin 1 and Bcl-2, preventing host cell apoptosis to generate a persistent bacterial infection. Cell Death Differ 17, 421-438.

Vogel, J. P. (2004). Turning a tiger into a house cat: using Legionella pneumophila to study Coxiella burnetii. Trends Microbiol 12, 103-105.

Vogel, J. P. \& Isberg, R. R. (1999). Cell biology of Legionella pneumophila. Curr Opin Microbiol 2, 30-34.

Voth, D. E. \& Heinzen, R. A. (2007). Lounging in a lysosome: the intracellular lifestyle of Coxiella burnetii. Cell Microbiol 9, 829-840.

Voth, D. E. \& Heinzen, R. A. (2009). Coxiella type IV secretion and cellular microbiology. Curr Opin Microbiol 12, 74-80.

Voth, D. E., Howe, D. \& Heinzen, R. A. (2007). Coxiella burnetii inhibits apoptosis in human THP-1 cells and monkey primary alveolar macrophages. Infect Immun 75, 4263-4271.

Voth, D. E., Howe, D., Beare, P. A., Vogel, J. P., Unsworth, N., Samuel, J. E. \& Heinzen, R. A. (2009). The Coxiella burnetii ankyrin repeat domain-containing protein family is heterogeneous, with C-terminal truncations that influence Dot/Icm-mediated secretion. J Bacteriol 191, 4232-4242.

Waag, D. M. (2007). Coxiella burnetii: host and bacterial responses to infection. Vaccine 25, 7288-7295.

Waag, D. M., Byrne, W. R., Estep, J., Gibbs, P., Pitt, M. L. M. \& Banfield, C. M. (1999). Evaluation of cynomolgus (Macaca fascicularis) and rhesus (Macaca mulatta) monkeys as experimental models of acute Q fever after aerosol exposure to phase I Coxiella burnetii. Lab Anim Sci 49, 634-638. 
Waag, D. M., England, M. J., Tammariello, R. F., Byrne, W. R., Gibbs, P., Banfield, C. M. \& Pitt, M. L. M. (2002). Comparative efficacy and immunogenicity of $\mathrm{Q}$ fever chloroform: methanol residue (CMR) and phase I cellular (Q-Vax) vaccines in cynomolgus monkeys challenged by aerosol. Vaccine 20, 2623-2634.

WHO (1970). Health Aspects of Chemical and Biological Weapons, 1st edn. Geneva: World Health Organization.

WHO (2004). Health Aspects of Chemical and Biological Weapons, 2nd edn. Geneva: World Health Organization.

Willems, H., Ritter, M., Jäger, C. \& Thiele, D. (1997). Plasmidhomologous sequences in the chromosome of plasmidless Coxiella burnetii Scurry Q217. J Bacteriol 179, 3293-3297.

Willems, H., Jäger, C. \& Baljer, G. (1998). Physical and genetic map of the obligate intracellular bacterium Coxiella burnetii. J Bacteriol 180, 3816-3822.

Williams, J. C., Peacock, M. G. \& Mccaul, T. F. (1981). Immunological and biological characterization of Coxiella burnetii, phases I and II, separated from host components. Infect Immun 32, 840-851.

Williams, J. C., Hoover, T. A., Waag, D. M., Banerjeebhatnagar, N., Bolt, C. R. \& Scott, G. H. (1990). Antigenic structure of Coxiella burnetii. A comparison of lipopolysaccharide and protein antigens as vaccines against Q fever. Ann N Y Acad Sci 590, 370-380.
Zamboni, D. S., McGrath, S., Rabinovitch, M. \& Roy, C. R. (2003). Coxiella burnetii express type IV secretion system proteins that function similarly to components of the Legionella pneumophila Dot/ Icm system. Mol Microbiol 49, 965-976.

Zhang, G. \& Samuel, J. E. (2003). Identification and cloning potentially protective antigens of Coxiella burnetii using sera from mice experimentally infected with Nine Mile phase I. Ann N Y Acad Sci 990, 510-520.

Zhang, Y. X., Zhi, N., Yu, S. R., Li, O. J., Yu, G. O. \& Zhang, X. (1994). Protective immunity induced by $67-\mathrm{K}$ outer-membrane protein of phase I Coxiella burnetii in mice and guinea pigs. Acta Virol 38, 327332.

Zhang, G., Russell-Lodrigue, K. E., Andoh, M., Zhang, Y., Hendrix, L. R. \& Samuel, J. E. (2007). Mechanisms of vaccine-induced protective immunity against Coxiella burnetii infection in BALB/c mice. J Immunol 179, 8372-8380.

Zuerner, R. L. \& Thompson, H. A. (1983). Protein synthesis by intact Coxiella burnetii cells. J Bacteriol 156, 186-191.

Zusman, T., Yerushalmi, G. \& Segal, G. (2003). Functional similarities between the $\mathrm{icm} / \mathrm{dot}$ pathogenesis systems of Coxiella burnetii and Legionella pneumophila. Infect Immun 71, 37143723. 